\title{
Influence of Gamma Radiation on Mechanical Properties of Jute Fabric-Reinforced Polymer Composites
}

\author{
K.Z.M. Abdul Motaleb ${ }^{1}{ }^{\oplus}$, Rimvydas Milašius ${ }^{1, *}$ and Abdul Ahad ${ }^{2}$ \\ 1 Faculty of Mechanical Engineering and Design, Kaunas University of Technology, 51424 Kaunas, Lithuania; \\ k.motaleb1@ktu.edu \\ 2 Department of Textile Engineering, BGMEA University of Fashion and Technology, Dhaka 1230, Bangladesh; \\ abdulahadallsheikh@gmail.com \\ * Correspondence: rimvydas.milasius@ktu.lt
}

Received: 6 August 2020; Accepted: 11 September 2020; Published: 13 September 2020

\begin{abstract}
Woven jute fabric was used as a reinforcing material for making two types of composite, named Jute/PR and Jute/Epoxy, with two different matrixes of polyester resin and epoxy, respectively, by hand layup techniques. Five different doses of gamma radiation from 100 to $500 \mathrm{krad}$ were used to investigate the effects of the mechanical properties of the composites and the jute fabrics. Though gamma radiation improved the mechanical properties, such as the tensile strength (TS) and Young's modulus (Y), and decreased the elongation at break \% (Eb\%) of the composites, it deteriorated all these properties for jute fabrics. The highest values of TS and $\mathrm{Y}$ and the lowest value of $\mathrm{Eb} \%$ were found to be $39.44 \mathrm{Mpa}, 1218.33 \mathrm{Mpa}$, and $7.68 \%$ for the Jute/PR; and $48.83 \mathrm{Mpa}, 1459.67 \mathrm{Mpa}$, and $3.68 \%$ for the Jute/Epoxy composites, respectively, at a $300 \mathrm{krad}$ gamma radiation dose. A further increase in dose altered all these properties; thus, $300 \mathrm{krad}$ was found to be the optimum dose for both of the composites. Between the two composites, gamma radiation influenced the Jute/PR composite more than the Jute/Epoxy composite.
\end{abstract}

Keywords: jute fabric; epoxy and polyester resin; natural composites; gamma radiation; mechanical properties

\section{Introduction}

With the increase in environmental consciousness, community interest, and new environmental regulations, the use of environmentally friendly materials is increasing day by day [1,2]. Natural fibers are considered an eco-friendly material, and replace synthetic materials and their related products for lower weight and energy conservation applications [3,4]. A variety of natural fibers such as banana, jute, flax, pineapple leaf, bamboo, eucalyptus pulp, coconut, palm, sansevieria leaf, sisal, sugarcane fiber, cotton, ramie bast, date, malva, abaca leaf, kenaf bast, and hemp are being used as reinforcing materials in polymer composite materials to diversify their application from the automotive to biomedical fields [5,6]. Natural fiber-reinforced polymer composites (NFRPC) are extensively attractive in diversified applications from household to aerospace settings due to their light weight, biodegradability, renewability, high strength, high stiffness, good corrosion resistivity, enhanced energy recovery, lower fabrication cost, and many more [7-11].

In this research, we used jute fabric as a reinforcing material along with two different polymer matrixes-i.e., polyester resin and epoxy resin. Jute is one of the cheap ligno-cellulosic fibers easily available in fiber and fabric form, and this fiber is the most promising reinforcement material for the production of bio-composites and bio-plastics due to its high content of cellulose $(61-72 \%)$, 
hemicellulose (14-20.4\%), lignin (12-13\%), and pectin $(0.2 \%)[10,12-14]$. Lots of research can be found studying the different mechanical properties of jute fiber, which have acceptable mechanical properties [15]. Although the use of jute fabric as a reinforcing material is not so common as jute fibers over the years, several researchers have already studied different properties of jute fabric-reinforced polymer composites [16-19]. Mohanty et al. investigated the influence of chemical surface modification on the properties of biodegradable jute fabric polyester amide composites [16]. The mechanical, inter-laminar shear, notched strength, and fracture criterion properties of untreated woven jute and glass fabric-reinforced polyester hybrid composites were investigated by Ahmed et al. [18,19]. However, jute fabric as a reinforcing material can be a perfect choice because of their higher productivity, structural customization possibility, good molding ability, and lack of need for cold storage [20].

There is no doubt that NFRPC materials have a lot of advantages, but they have several disadvantages as well. One of the main disadvantages of natural fiber as a reinforcing material is its hydrophilic nature, responsible for moisture absorption, which may cause the swelling and maceration of the fibers, thus significantly decreasing their mechanical properties [13]. As jute fiber absorbs moisture to a great extent, having a moisture regain of $13.75 \%$, it has poor wettability with an organic matrix resin, resulting in a weak interfacial bonding between the fibers and commercially available resins such as polyester resin, epoxy resin, phenolic resin, amino resin, etc. [21,22].

To get rid of this, various kinds of surface treatments, such as chemical, thermal, plasma discharge, electrochemical, rare earth solution, and gamma radiation, can be applied to increase the adhesion among the fibers and matrixes [23]. Among them, gamma radiation can be a great choice due to some advantages, such as it being less time consuming, having an uninterrupted operation, its environment friendliness, its design flexibility, etc. [24,25]. Gamma radiation is a strong ionizing radiation which can rearrange the internal structure of the material and reduce its hydrophilic nature, which helps with better crosslinking between the natural fiber and matrix [26]. Many researchers have worked on the effect of gamma radiation on composite materials. Haydaruzzaman et al. investigated the mechanical performance after treating jute fabric-reinforced polypropylene composites with gamma radiation, and found that irradiated composites showed better mechanical properties than all other non-irradiated composites [27]. Gamma radiation's effect on mechanical properties was also studied on raw and polyethylene glycol modified bleached jute-reinforced polyester composite by Hoque et al., who found that gamma radiation improved the mechanical properties up to a certain level, then started to decrease [28]. Gamma and electron beam radiation was also applied to a PAN carbon fiber-based composite by Jafari et al., and they found that, by increasing the gamma and electron doses, the thermal behavior of the composites indicated a higher decomposition degree as a function of the temperature [23]. Vasco et al. worked on the gamma radiation effect on sisal/polyurethane composites without coupling agents, and Wan et al. investigated the effect of gamma radiation on the mechanical performance of carbon fiber composites [29,30]. Patra et al. analyzed the mechanical properties of bio-composites using gamma-irradiated fibers of luffa cylindrical [31]. The effects of the layering sequence and gamma radiation on the mechanical properties and morphology of Kevlar/oil palm empty fruit bunch (EFB)/epoxy hybrid composites were investigated by Amir et al. [32]. Khan et al. studied the effect of gamma radiation on the physic-mechanical properties of starch-treated jute yarn-reinforced polypropylene composites [26]. Similarly, some more researchers studied the effects of gamma radiation on the mechanical and other properties of different composite materials [25,33-36]. Besides these, Gonzalo et al. studied the effects of gamma radiation on the physicochemical properties of polyester resin. Their study found that commercially available catalysts are insufficient for the complete polymerization of polyester resin where gamma radiation can complete such activity, thus resulting in a high degree of cross-linking and morphological change on the surface when it is used as a matrix on a composite material [37].

The application of gamma radiation on composite materials is not a new idea. Most of the researchers investigated gamma radiation's effects on the different properties of composite materials, but nobody has investigated the elongation property, which is also very important for composites, 
which especially must keep their geometry at the time of usage. In our previous study, we found some interesting results on the elongation properties of natural composite materials after gamma radiation that influence us to complete further investigation [38]. In this study, the effects of gamma radiation on the elongation properties of composite materials with other mechanical properties were investigated in more detail. Gamma radiation's effects on the reinforcing material of jute fabrics were also studied. This research would be very interesting for composite manufactures who want to improve the mechanical properties of natural fiber-reinforced polymer composites and fix their geometry during the time of use.

\section{Materials and Methods}

\subsection{Materials}

Two types of composite materials, (1) jute fabric-reinforced polyester resin composite (Jute/PR) and (2) jute fabric-reinforced epoxy resin composite (Jute/Epoxy), are used for different doses of gamma radiation. Jute fabric was collected from the Bangladesh Jute Research Institute, Dhaka, Bangladesh. The specifications of jute fabric are mentioned in Table 1. Epoxy resin, unsaturated polyester resin (UPR), and a catalyst named methyl ethyl ketone peroxide (MEKP) were brought from Nasim Plastic Industries Limited, Dhaka, Bangladesh.

Table 1. Specification of jute fabric.

\begin{tabular}{cc}
\hline Quality Parameters & Jute Fabric \\
\hline Weave & Plain \\
Linear densities of yarns & $190 \mathrm{tex}$ \\
Densities in warps and in wefts & $6 \mathrm{~cm}^{-1}$ \\
Surface density & $229 \mathrm{~g} / \mathrm{m}^{2}$ \\
\hline
\end{tabular}

\subsection{Methods}

\subsubsection{Fabrication of Composite}

The hand layup technique was used for making all the composite samples. For both the composites, jute fabric was used as a reinforcing material. Polyester resin and epoxy resin were used as the matrix for the Jute/PR and Jute/Epoxy composites, respectively. The jute fabrics with a size of $19 \times 19 \mathrm{~cm}$, glass plates, and some mylar papers with a size of $30 \times 30 \mathrm{~cm}$ were prepared. Then, polyester resin for the Jute/PR composite and epoxy resin for the Jute/Epoxy composite were taken according to the weight of fabric in a beaker with $2 \%$ hardener and mixed vigorously with an agitator until it became a uniform paste. Firstly, a piece of mylar paper was placed on the glass plate. Then, 1/4 of the prepared paste was poured on to the mylar paper and defused manually according to the area of jute fabric by a brush. Then, 1 ply of the fabric was laid on the matrix paste and attached with a heavy roller. Similarly, another ply of fabric was attached with the previous one after pouring $1 / 4$ of the mixture again. In this way, a third ply of fabric was also attached to the matrix. Finally, the last $1 / 4$ of the mixture was poured over the third layer of jute fabric, and we placed another mylar paper and glass plate on it to make a sandwich-like structure. A $15 \mathrm{~kg}$ dead weight was then applied on the whole prepared structure for 24 h. After that time, the applied dead weight was withdrawn, and two layers of the mylar paper were released from the composite. In this way, all the composites were prepared for further investigation. The photographs of the resultant composites along with the reinforced jute fabrics are presented in Figure 1. 

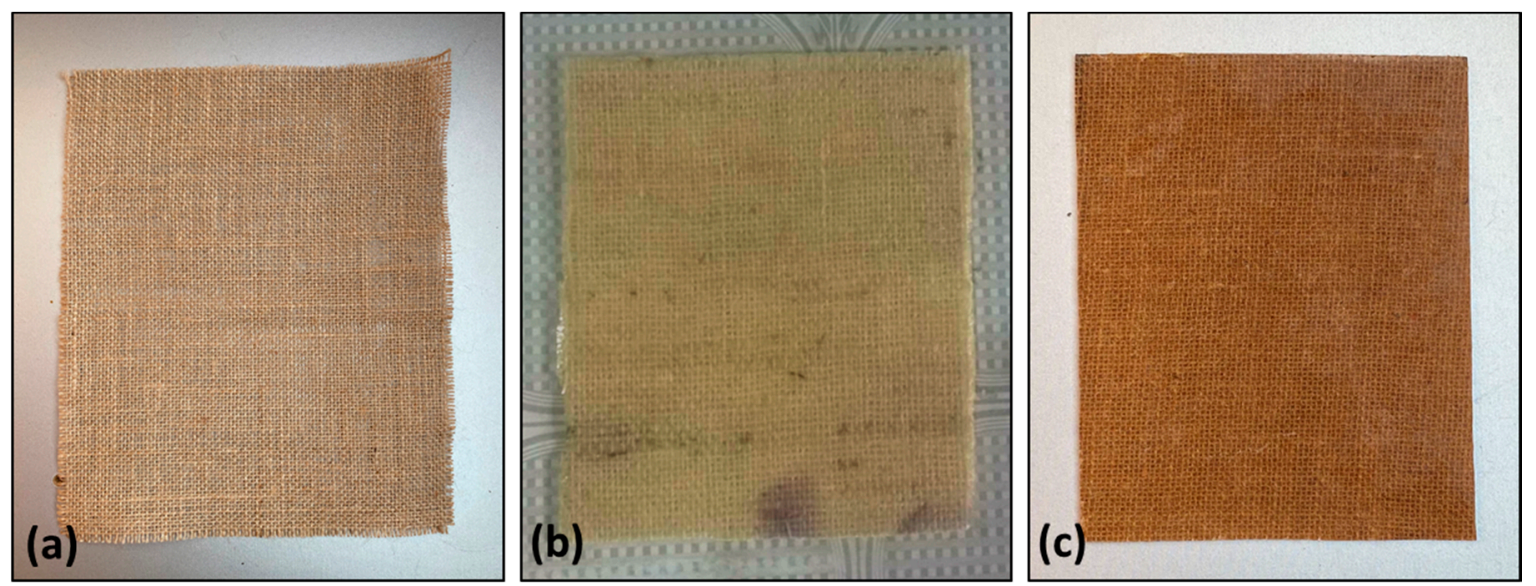

Figure 1. Photographs of (a) reinforced jute fabric, (b) resultant Jute/PR composites, and (c) resultant Jute/Epoxy composites.

\subsubsection{Sampling}

Digital slide calipers were used for calculating the dimensions of the composites. Measurements were taken from three different places of each sample and we made an average from them. All the composites were found to have a similar thickness of $2.41 \pm 0.02 \mathrm{~mm}$. A total of 30 samples (15 for Jute/PR and 15 for Jute/Epoxy) with dimensions of $150 \times 15 \mathrm{~mm}$ were prepared for treating with gamma radiation.

\subsubsection{Gamma Radiation}

The machine that is used for gamma radiation is named the Co-60 gamma source (model: 650 No. 11R). It is a capsule type of electromechanical system which can be controlled by a remote. A source GBS-98 is used for loading the gamma beam, which is equivalent to 36 double encapsulated capsules. The prepared composites were irradiated with various doses from 100 to $500 \mathrm{krad}$ with intervals of 100 krad by this source.

\subsubsection{Mechanical Properties}

A Universal Testing Machine (Model: H50KS-0404) was used for investigating all the tensile properties, such as $T S, E b \%$, and $Y$, at the Institute of Radiation and Polymer Technology Laboratory, British Airways Executive Club (BAEC), Dhaka, Bangladesh. The specimens were prepared according to the American Society for Testing and Materials (ASTM) D638 standard for composites and ASTM D5034 for jute fabrics. The crosshead speed of $10 \mathrm{~mm} / \mathrm{min}$ gauge length of $50 \mathrm{~mm}$ were maintained for the composites, and the crosshead speed of $300 \mathrm{~mm} / \mathrm{min}$ and gauge length of $75 \mathrm{~mm}$ were maintained for the jute fabrics. Equations (1)-(3) were used for measuring the $T S, E B \%$, and $Y$, respectively [39].

$$
T S=\frac{F_{\max }}{A},
$$

where $F_{\max }=$ maximum load and $A=$ cross-sectional area.

$$
E B(\%)=\frac{\Delta L_{b}}{L_{0}} \times 100,
$$

where $\Delta L_{b}=$ extension at break point and $L_{0}=$ initial length of the sample.

$$
\Upsilon M=\frac{d \sigma}{d \varepsilon},
$$

where $d \sigma=$ stress at yield point and $d \varepsilon=$ strain at yield point. 


\section{Results and Discussion}

\subsection{Mechanical Properties of Jute Fabrics}

The effect of gamma radiation on the mechanical properties-i.e., tensile strength (TS), elongation at break percentage $(\mathrm{Eb} \%)$, and Young's modulus $(\mathrm{Y})$ — of jute fabrics was monitored (all the average values were calculated from three tests). All the dependencies in this paper are described as a polynomial curve of 2 nd order. It is clear from Figure 2 that, with the increase in the gamma dose, all the mechanical properties decreased significantly. The TS of the jute fabric decreased about $70 \%$ when treated with 500 krad compared to the untreated fabric. Similarly, the Eb\% and Y also decreased $57 \%$ and $58 \%$, respectively, when treated with a similar dose of $500 \mathrm{krad}$ compared to the untreated fabric. This decreasing trend for all the mechanical properties-i.e., TS, Eb\%, and Y-of jute fabric is due to the penetration of a very strong ionizing radiation such as gamma radiation into the fiber, which leads to breaking the primary bonds of the cellulose structure, which may change the middle lamella and, consequently, reduce the ultimate cells of the fibers [40]. This severe destruction of the fibers may responsible for the decreasing of all the mechanical properties of the jute fabrics. Even the elongation properties were decreased with the decrease in the modulus. Though this is an irregular behavior for a material, this may happen due to the heavy breakage of the polymeric structure that turned it into tiny molecules and caused it to lose its main physical state. Additionally, it made the material more amorphous and brittle, and hence caused it to break immediately under a tensile load without much extension.

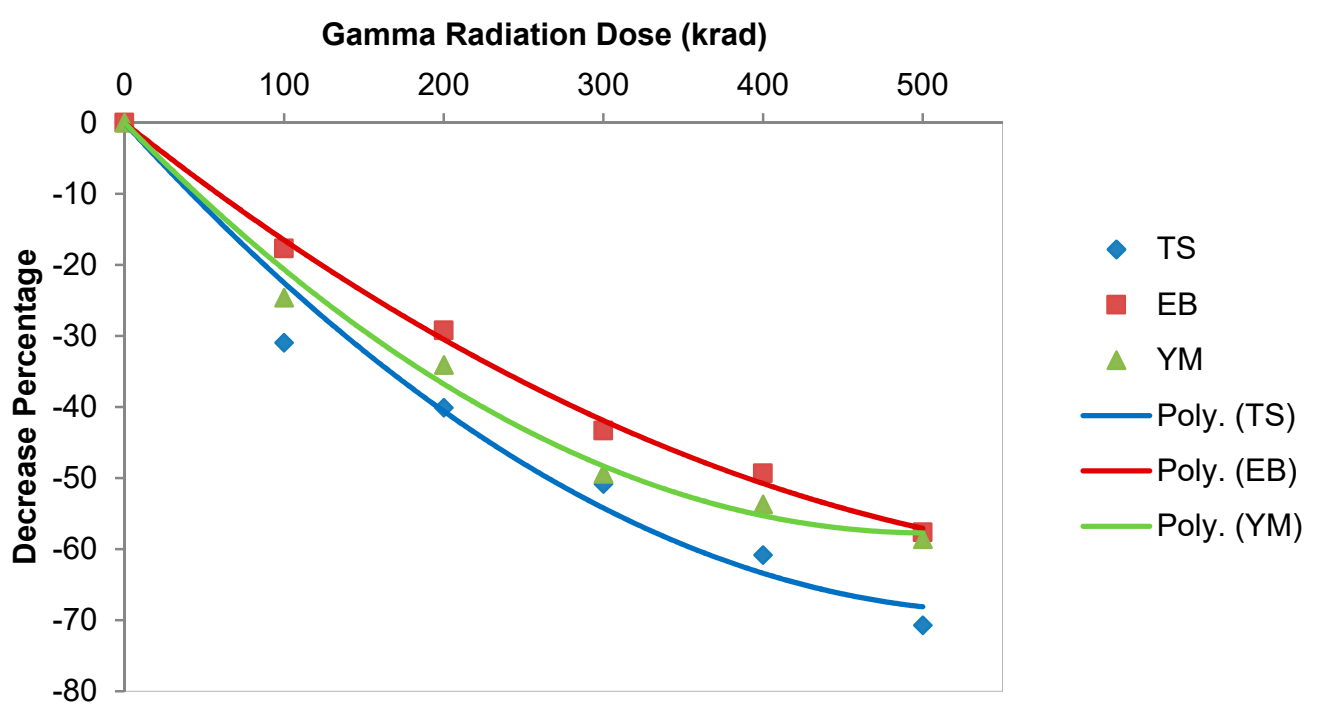

Figure 2. Gamma radiation effects on the tensile strength (TS), elongation at break \% (Eb\%), and Young's modulus (Y) of the jute fabric.

\subsection{Tensile Strength (TS) of Jute Composites}

Figure 3 depicts the effect of gamma radiation on the tensile strength of the Jute/PR and Jute/Epoxy composites. The trend line for both the composites clearly shows that gamma radiation increases the TS remarkably up to a certain level. The maximum TS for the Jute/PR composite was found to be 39.44 $\mathrm{MPa}$ at a $300 \mathrm{krad}$ dose of gamma irradiation, and maximum value of TS for the Jute/Epoxy composite was found to be $48.83 \mathrm{MPa}$ at the same dose of gamma radiation. The TS increased dramatically by $98 \%$ and $89 \%$ for the Jute/PR and Jute/Epoxy composites, respectively, at $300 \mathrm{krad}$, compared with the non-irradiated composites. This improvement in the TS is due to the better cross-linking and, hence, better adhesion between the fiber and matrix after the gamma radiation, which results in the more oriented polymeric structure of the composites [28,40,41]. Gamma radiation is known as a strong ionizing radiation which can penetrate easily into composite materials and interrupt the internal 
structure of fiber and matrix. The carbon-carbon bonds of the material can also be destroyed by this radiation, which may lead to producing free radicals and consequently alter the chemical structures and physical properties of the material [27,37]. It can also form a large molecule by cross-linking among the small molecules [34,40]. Thus, this increases the TS of the materials. One of the main obstacles for improving the mechanical properties is the moisture content, which may also be removed by gamma radiation and leads to an increase in the TS [24,35].

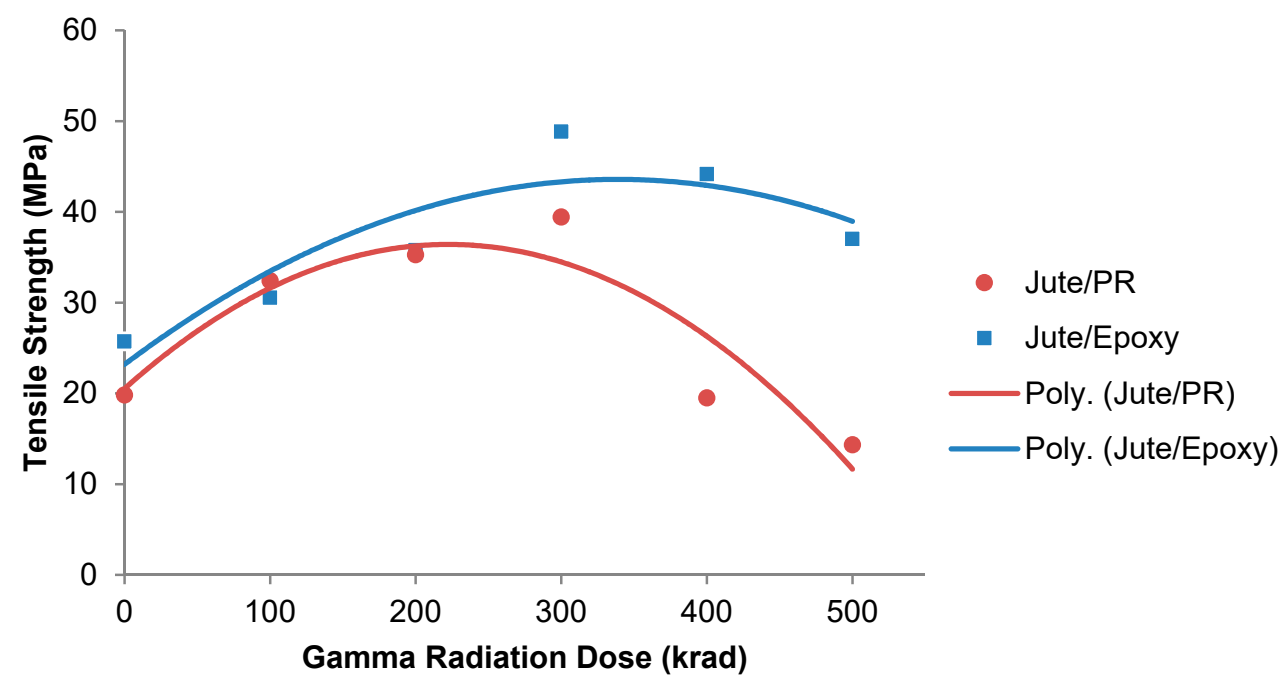

Figure 3. Gamma radiation effects on the tensile strength (TS) of the Jute/PR and Jute/Epoxy composites.

However, further increasing from the dose of $300 \mathrm{krad}$ leads to a decrease in the TS. It was found that, at a dose of $500 \mathrm{krad}$ of gamma radiation, the TS decreased 63\% from the maximum TS for the Jute/PR composite, which is even $27 \%$ lower than the non-irradiated composite. Similarly, the TS of the Jute/Epoxy composite decreased $24 \%$ at a dose of $500 \mathrm{krad}$. This opposite trend after a certain level of gamma radiation dose is due to two opposing phenomena-namely, the photo cross-linking and photo degradation that take place simultaneously under gamma radiation. At lower doses, free radicals are stabilized by a combination reaction and results in photo cross-linking among the molecules, which increases the TS. Inversely, at a higher dose, the backbone of the chain may lead to break. Consequently, the polymers are degraded into small fragments, and this results in a decrease in the tensile properties [34,40]. Severe degradation of polymer molecules may also occur at high dose such as $500 \mathrm{krad}$, and results in the lowest TS, even lower than that of the non-irradiated composites. Though both the composites behave quite similarly after the gamma radiation, there is a little influence on the matrix as well. Polyester resin affects the TS more than the epoxy resin after gamma radiation, as it increased the TS up to $98 \%$, whereas in epoxy it was $89 \%$. However, the PR composite is less stable in gamma radiation, as it decreased the TS more quickly during the gamma radiation dose than the epoxy composite.

\subsection{Elongation at Break (Eb\%) of Jute Composites}

The effect of gamma radiation on the elongation properties of the composites are revealed in Figure 4 . The curves clearly indicate that the elongation at break percentage $(\mathrm{Eb} \%)$ gradually decreased with the increase in the gamma radiation dose up to a certain level of $300 \mathrm{krad}$, then started to increase continuously. At a dose of $300 \mathrm{krad}$ of gamma radiation, the $\mathrm{Eb} \%$ decreased from the maximum to 7.68 from the $\mathrm{Eb} \%$ of the non-irradiated composite of 23.53 for the Jute/PR composite, and the $\mathrm{Eb} \%$ decreased to 3.68 at a dose of $300 \mathrm{krad}$ from the $6.06 \mathrm{~Eb} \%$ of the non-irradiated Jute/Epoxy composite. Elongation is a totally opposite property to tensile strength. The decreasing trend of Eb\% with the increase in gamma radiation is due to the opposite phenomenon to TS. As discussed above, gamma radiation increases the bonding among the fibers and matrix, making them highly oriented structures; 
this may lead to the highest amount of crosslinking being formed between the polyester-polyester and jute-polyester molecules for the Jute/PR composites, and the epoxy-epoxy and jute-epoxy molecules for the Jute/Epoxy composites [28]. This higher crosslinking among the molecules may lead to a higher crystallinity and thus restrict the segmental motion of the polymer chains, making the composite break at a lower percentage of elongation [42].

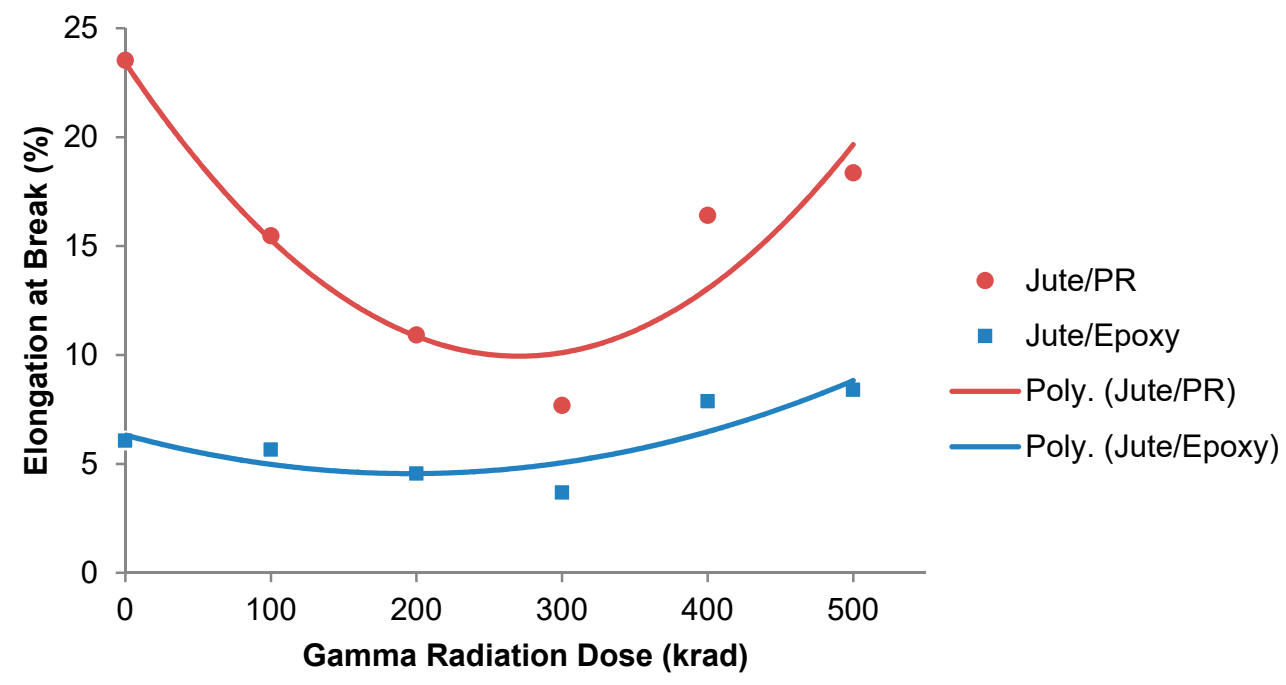

Figure 4. Gamma radiation effects on the elongation at break \% (Eb\%) of the Jute/PR and Jute/Epoxy composites.

This can also be explained by the definition of elongation, the amount of extension of a material in its length is called elongation. If the length extension is less, then elongation becomes less. Contrariwise, both the $\mathrm{Y}$ and TS are inversely proportional to elongation. Thus, for higher values of TS, obviously elongation will be lower and that is happening here. However, further increasing of gamma radiation doses, gradually increased the $\mathrm{Eb} \%$ for both the composites. It was found that, $\mathrm{Eb} \%$ increased to 18.36 and 8.4 for Jute/PR and Jute/Epoxy composite respectively at $500 \mathrm{krad}$ of dose. This is because of photo-degradation occurred at higher doses of gamma radiation that leads to break the main chain of the polymer and make them into small fragments. This also breaks the cross-linking among the molecules of fiber and matrix. That creates an irregular polymeric structure and results in more amorphous regions in the materials, which leads to greater elongation percentages [43]. It is also found that the elongation properties after gamma radiation were affected more in the PR composite than in the epoxy composite. The Eb\% decreased from the maximum $67 \%$ and $39 \%$ for the Jute/PR and Jute/Epoxy composites, respectively, after $300 \mathrm{krad}$ of gamma radiation. This may have occurred due to the structural differences between the two matrixes.

\subsection{Young's Modulus (Y) of Jute Composites}

Figure 5 shows the gamma radiation effect on the Young's modulus of the composites. It is observed that Young's modulus (Y) of the Jute/PR composite gradually increased about 5 times higher than the non-irradiated composite, from 235.33 MPa to $1218.33 \mathrm{MPa}$, at a dose of $300 \mathrm{krad}$. Similarly, the $\mathrm{Y}$ of the Jute/Epoxy composite increased about $115 \%$ compared to the non-irradiated composite, 678.67 $\mathrm{MPa}$ to $1459.63 \mathrm{MPa}$, at the same dose of gamma radiation, and then showed a continuously decreasing trend. Y decreased $71 \%$ and $29 \%$ for the Jute/PR and Jute/Epoxy composites, respectively, from the maximum value at a dose of $500 \mathrm{krad}$. 


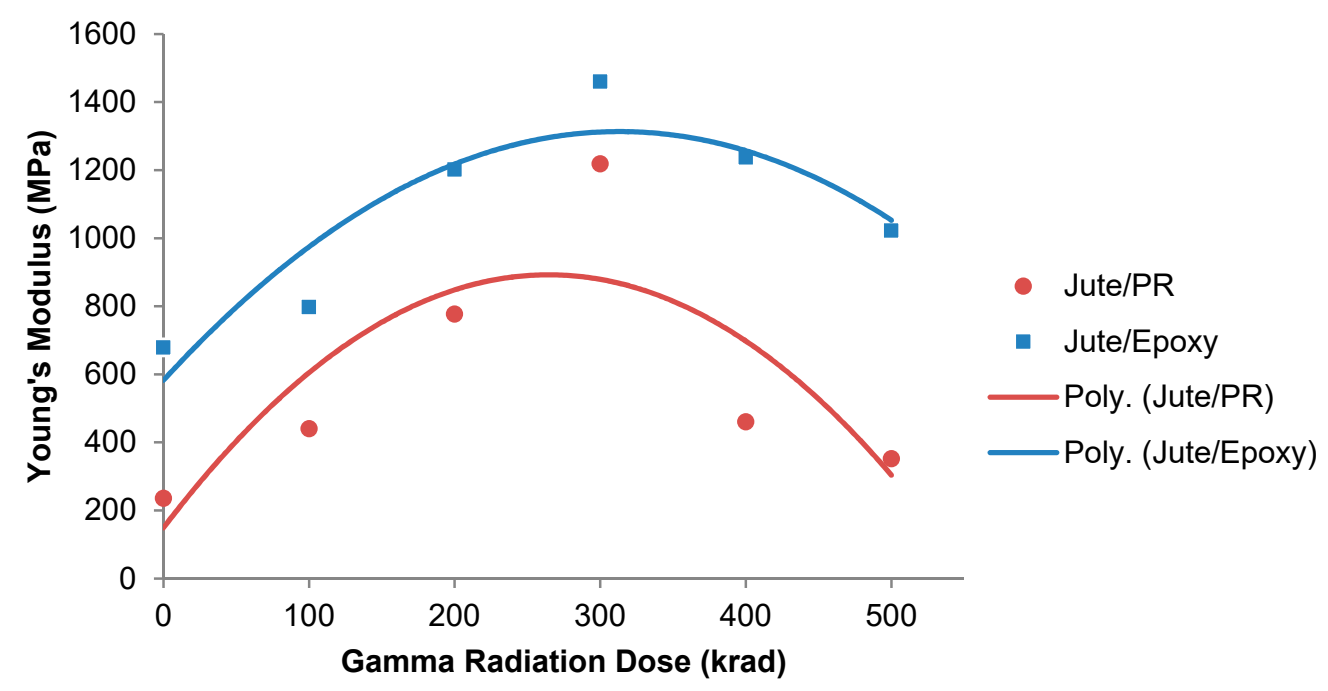

Figure 5. Gamma radiation effects on the Young's modulus (Y) of the Jute/PR and Jute/Epoxy composites.

The Young's modulus shows a similar trend to tensile strength for both the composites. Gamma treatment increases the bond strength by producing active sites; this also increases the cross-linking between the fibers, resulting in the increasing of the Young's modulus [27,35]. Further increase in gamma radiation decreases the Young's modulus because of the polymer main chain degradation, named chain scission, caused by over-radiation [34]. Although both the composite show similar trends under gamma radiation, the Jute/PR composite is affected a little more than the Jute/Epoxy composite.

\section{Conclusions}

In our study, the effect of gamma radiation on the mechanical properties, especially the elongation properties, of jute fabric and two types of jute fabric-reinforced composites-i.e., Jute/PR and Jute/Epoxy-were studied. It was found that gamma radiation improved the tensile strength and Young's modulus up to a certain level of irradiation dose ( $300 \mathrm{krad})$, but a further increase in dose gradually decreased the properties. Totally inverse behavior was found in the elongation properties of the composites, as the elongation percentage at break is inversely proportional with the increase in the gamma radiation dose, also up to a certain level of $300 \mathrm{krad}$, and then increased with the increase in dose. Thus, $300 \mathrm{krad}$ was found to be the optimum dose of gamma radiation because there was the highest tensile strength, highest Young's modulus, and lowest elongation at this dose for both the composites. Though the gamma radiation improved the mechanical properties of all the composites, it had strong negative effects on the mechanical properties of the jute fabrics, as it decreased all the values approximately $60-70 \%$ at the $500 \mathrm{krad}$ dose compared to the non-irradiated samples. Between the two composites, the Jute/PR composite shows more effect under gamma radiation than the Jute/Epoxy composite, but the epoxy composite is more stable under radiation. As gamma radiation decreases the elongation properties and increases other mechanical properties, such as tensile strength and Young's modulus, up to a certain level of radiation dose, it could be an interesting option for the natural composite manufacturer to make a high-strength material, but the optimum level of dose must be maintained.

Author Contributions: Conceptualization, K.Z.M.A.M. and R.M.; methodology, K.Z.M.A.M. and A.A.; software, K.Z.M.A.M.; validation, K.Z.M.A.M., R.M. and A.A.; formal analysis, R.M.; investigation, K.Z.M.A.M. and R.M.; resources, K.Z.M.A.M. and A.A.; data curation, K.Z.M.A.M. and A.A.; writing-original draft preparation, K.Z.M.A.M.; writing-review and editing, R.M. and A.A.; visualization, K.Z.M.A.M.; supervision, R.M.; project administration, R.M.; funding acquisition, not applicable. All authors have read and agreed to the published version of the manuscript.

Funding: This research received no external funding.

Conflicts of Interest: The authors declare no conflict of interest. 


\section{References}

1. Mohammed, L.; Ansari, M.N.M.; Pua, G.; Jawaid, M.; Islam, M.S. A review on natural fiber reinforced polymer composite and its applications. Int. J. Polym. Sci. 2015, 2015. [CrossRef]

2. Ates, B.; Koytepe, S.; Ulu, A.; Gurses, C.; Thakur, V.K. Chemistry, structures, and advanced applications of nanocomposites from biorenewable resources. Chem. Rev. 2020, 9304-9362. [CrossRef] [PubMed]

3. Sanjay, M.R.; Arpitha, G.R.; Naik, L.L.; Gopalakrishna, K.; Yogesha, B. Applications of natural fibers and its composites: An overview. Nat. Resour. 2016, 7, 108. [CrossRef]

4. Singha, A.; Thakur, V.K. Synthesis and characterization of pine needles reinforced RF matrix based biocomposites. Eur. J. Chem. 2008, 5. [CrossRef]

5. Saba, N.; Jawaid, M.; Alothman, O.A.; Paridah, M.T. A review on dynamic mechanical properties of natural fibre reinforced polymer composites. Constr. Build. Mater. 2016, 106, 149-159. [CrossRef]

6. Singha, A.; Thakur, V.K. Mechanical, thermal and morphological properties of grewia optiva fiber/polymer matrix composites. Polym. Technol. Eng. 2009, 48, 201-208. [CrossRef]

7. Ameer, M.H.; Nawab, Y.; Ali, Z.; Imad, A.; Ahmad, S. Development and characterization of jute/polypropylene composite by using comingled nonwoven structures. J. Text. Inst. 2019, 1-8. [CrossRef]

8. Xiao, Z.; Pei, L.; Zhang, F.; Sun, Y.; Geng, L.; Wu, J.; Tong, J. Parameter Measurement of Biaxial Braided Composite Preform Based on Phase Congruency. Autex Res. J. 2019, 19, 8-16. [CrossRef]

9. Ashir, M.; Nocke, A.; Cherif, C. Effect of the Position of Defined Local Defect on the Mechanical Performance of Carbon-Fiber-Reinforced Plastics. Autex Res. J. 2019, 19, 74-79. [CrossRef]

10. Wahab, N.; Srinophakun, P.; Hussain, Q.; Chaimahawan, P. Performance of Concrete Confined with a Jute-Polyester Hybrid Fiber Reinforced Polymer Composite: A Novel Strengthening Technique. Fibers 2019, 7, 72. [CrossRef]

11. Singha, A.; Thakur, V.K. Fabrication and characterization of H. sabdariffa fiber-reinforced green polymer composites. Polym. Plast. Technol. Eng. 2009, 48, 482-487. [CrossRef]

12. Tripathi, P.; Gupta, V.K.; Dixit, A.; Misra, R.K. Development and characterization of low cost jute, bagasse and glass fiber reinforced advanced hybrid epoxy composites. AIMS Mater. Sci. 2018, 5, 320-337. [CrossRef]

13. Rahman, R.; Huque, M.; Islam, N.; Hasan, M. Improvement of physico-mechanical properties of jute fiber reinforced polypropylene composites by post-treatment. Compos. Part A Appl. Sci. Manuf. 2008, 39, 1739-1747. [CrossRef]

14. Das, S. Mechanical properties of waste paper/jute fabric reinforced polyester resin matrix hybrid composites. Carbohydr. Polym. 2017, 172, 60-67. [CrossRef]

15. Ashraf, M.A.; Zwawi, M.; Mehran, M.T.; Kanthasamy, S.; Bahadar, A. Jute based bio and hybrid composites and their applications. Fibers 2019, 7, 77. [CrossRef]

16. Mohanty, A.; Khan, M.; Hinrichsen, G. Influence of chemical surface modification on the properties of biodegradable jute fabrics-Polyester amide composites. Compos. Part A Appl. Sci. Manuf. 2000, 31, 143-150. [CrossRef]

17. Gowda, T.M.; Naidu, A.; Chhaya, R. Some mechanical properties of untreated jute fabric-reinforced polyester composites. Compos. Part A Appl. Sci. Manuf. 1999, 30, 277-284. [CrossRef]

18. Ahmed, K.S.; Vijayarangan, S. Tensile, flexural and interlaminar shear properties of woven jute and jute-glass fabric reinforced polyester composites. J. Mater. Process. Technol. 2008, 207, 330-335. [CrossRef]

19. Ahmed, K.S.; Vijayarangan, S.; Naidu, A. Elastic properties, notched strength and fracture criterion in untreated woven jute-Glass fabric reinforced polyester hybrid composites. Mater. Des. 2007, 28, 2287-2294. [CrossRef]

20. Vo, D.M.P.; Hoffmann, G.; Cherif, C. Novel weaving technology for the manufacture of 2D net shape fabrics for cost effective textile reinforced composites. Autex Res. J. 2018, 18, 251-257. [CrossRef]

21. Mitra, B.; Basak, R.; Sarkar, M. Studies on jute-reinforced composites, its limitations, and some solutions through chemical modifications of fibers. J. Appl. Polym. Sci. 1998, 67, 1093-1100. [CrossRef]

22. Das, S.; Singha, A.K.; Chaudhuri, A.; Ganguly, P.K. Lengthwise jute fibre properties variation and its effect on jute-Polyester composite. J. Text. Inst. 2019, 1-8. [CrossRef]

23. Jafaria, R. Effect of Gamma and electron beam irradiation on PAN-carbon fiber composite. Braz. J. Radiat. Sci. 2016, 4, 1-11. [CrossRef] 
24. Khan, M.A.; Khan, R.A.; Haydaruzzaman; Hossain, A.; Khan, A.H. Effect of gamma radiation on the physico-mechanical and electrical properties of jute fiber-reinforced polypropylene composites. J. Reinf. Plast. Compos. 2009, 28, 1651-1660. [CrossRef]

25. Shubhra, Q.T.; Alam, A. Effect of gamma radiation on the mechanical properties of natural silk fiber and synthetic E-glass fiber reinforced polypropylene composites: A comparative study. Radiat. Phys. Chem. 2011, 80, 1228-1232. [CrossRef]

26. Khan, M.A.; Khan, R.A.; Haydaruzzaman; Ghoshal, S.; Siddiky, M.N.A.; Saha, M. Study on the physico-mechanical properties of starch-treated jute yarn-reinforced polypropylene composites: Effect of gamma radiation. Polym. Plast. Technol. Eng. 2009, 48, 542-548. [CrossRef]

27. Haydaruzzaman; Khan, R.A.; Khan, M.A.; Khan, A.H.; Hossain, M.A. Effect of gamma radiation on the performance of jute fabrics-reinforced polypropylene composites. Radiat. Phys. Chem. 2009, 78, 986-993. [CrossRef]

28. Hoque, M.A.; Bhuiya, A.K.; Saiduzzaman; Islam, A.; Khan, M.A. Effect of $\gamma$ (gamma)-radiation on mechanical properties of raw and polyethylene glycol-modified bleached jute reinforced polyester composite. World J. Eng. 2017, 14, 108-113. [CrossRef]

29. Wan, Y.Z.; Wang, Y.L.; Luo, H.L.; Chen, G.C.; Yuan, C.D. Effect of surface treatment of carbon fibers with gamma-ray radiation on mechanical performance of their composites. J. Mater. Sci. 2005, 40, 3355-3359. [CrossRef]

30. Vasco, M.C.; Neto, S.C.; Nascimento, E.M.; Azevedo, E. Gamma radiation effect on sisal/polyurethane composites without coupling agents. Polímeros 2017, 27, 165-170. [CrossRef]

31. Patra, S.; Mohanta, K.L.; Parida, C. Mechanical Analysis of Bio-Composites Using Gamma Irradiated Fibers of Luffa Cylindrica. In International Conference on Intelligent Computing and Communication Technologies; Springer: Berlin/Heidelberg, Germany, 2019.

32. Amir, S.M.; Suilan, M.T.B.H.; Jawaid, M.; Safri, S.N.A. Effects of layering sequence and gamma radiation on mechanical properties and morphology of Kevlar/oil palm EFB/epoxy hybrid composites. J. Mater. Res. Technol. 2019, 8. [CrossRef]

33. Das, S.C.; Paui, D.; Islam, J.M.M.; Khan, M.A. Effect of gamma radiation on the mechanical properties of PET felt reinforced polyester composites. In Proceedings of the International Conference on Mechanical, Industrial and Energy Engineering, Khulna, Bangladesh, 26-27 December 2016.

34. Shauddin, S.M.; Shaha, C.K.; Khan, M. Effects of fiber inclusion and $\gamma$ radiation on physico-mechanical properties of jute caddies reinforced waste polyethylene composite. J. Polym. Biopolym. Phys. Chem. 2014, 2, 91-97.

35. Ndiaye, D.; Badji, A.M.; Tidjani, A. Physical changes associated with gamma doses on wood/polypropylene composites. J. Compos. Mater. 2014, 48, 3063-3071. [CrossRef]

36. Xu, Z.; Huang, Y.; Zhang, C.; Liu, L.; Zhang, Y.; Wang, L. Effect of $\gamma$-ray irradiation grafting on the carbon fibers and interfacial adhesion of epoxy composites. Compos. Sci. Technol. 2007, 67, 3261-3270. [CrossRef]

37. Martínez-Barrera, G.; Martínez-López, A.; Vigueras, E. Effects of Gamma Radiation on the Physicochemical Properties of Polyester Resin and Its Use in Composite Materials, in Recycled Polyester; Springer: Berlin/Heidelberg, Germany, 2020; pp. 15-28.

38. Motaleb, K.A.; Islam, M.S.; Milašius, R. Effect of Gamma Radiation on the Mechanical Properties of Natural Fabric Reinforced Polyester Composites. Fibres Text. East. Eur. 2019, 27, 136. [CrossRef]

39. Kafi, A.; Abedin, M.Z.; Beg, M.D.H.; Pickering, K.L.; Khan, M.A. Study on the mechanical properties of jute/glass fiber-reinforced unsaturated polyester hybrid composites: Effect of surface modification by ultraviolet radiation. J. Reinf. Plast. Compos. 2006, 25, 575-588. [CrossRef]

40. Hossen, J. Evaluating the performance of gamma irradiated okra fiber reinforced polypropylene (PP) composites: Comparative study with jute/PP. Fash. Text. 2018, 5, 28.

41. Supreet, R.; Vinod, B.; Sudev, L. Effect of gamma irradiation on mechanical properties of natural fibers reinforced hybrid composites. Inter. J. Sci. Technol. Eng. 2015, 2, 15-23. 
42. EL-Zayat, M.M.; Abdel-Hakim, A.; Mohamed, M.A. Effect of gamma radiation on the physico mechanical properties of recycled HDPE/modified sugarcane bagasse composite. J. Macromol. Sci. 2019, 56, 127-135. [CrossRef]

43. Rahman, M.; Hoque, A.; Rahman, G.Y.; Azmi, M.M.; Gafur, M.A.; Khann, R.A.; Hossain, M.K. $\mathrm{Fe}_{2} \mathrm{O}_{3}$ nanoparticles dispersed unsaturated polyester resin based nanocomposites: Effect of gamma radiation on mechanical properties. Radiat. Eff. Defects Solids 2019, 174, 480-493. [CrossRef] 